\title{
What Should We Do Different, More, Start and Stop? Systematic Collection and Dissemination of Massage Education Stakeholder Views from the 2017 Alliance for Massage Therapy Educational Congress ${ }^{\dagger}$
}

\author{
Niki Munk, PhD, LMT, ${ }^{1,2}$ Jasmine Dyson-Drake, BS ${ }^{1}$ Diane Mastnardo, LMT $^{3}$ \\ ${ }^{1}$ Department of Health Sciences, Indiana University School of Health and Human Sciences-IUPUI, Indianapolis, IN, USA; \\ ${ }^{2}$ Australian Research Centre in Complementary and Integrative Medicine (ARCCIM), Broadway NSW, Australia; ${ }^{3}$ Massage \\ of Northern Ohio Practice Based Research Network, Cleveland, OH, USA
}

Introduction: The Future of MT and Bodywork Forum, held July 27 during the 2017 Alliance for Massage Therapy Education (AFMTE) Educational Congress in Tucson, Arizona, systematically gathered the thoughts and opinions of various massage education stakeholders through an exercise following the principles of the World Café model.

Methods: Forum attendees participated in three, concurrent 30-minute Breakout Group Sessions (Rounds) in three different adjacent rooms, focused on Continuing Education, Schools, or Employment. During each session, participants rotated for $3,2.5,2$, and $1.5 \mathrm{~min}-$ utes between four tables, asking what should be stopped, started, done differently, or changed in massage education related to the focus topic. Participants recorded their responses in marker on large Post-it ${ }^{\circledR}$ notes (3M, Maplewood, MN). These were reviewed by each of that round's participants who awarded "importance points" to each response, with 6 blue and 3 orange dots each worth 1 and 3 points, respectively. The Post-it ${ }^{\circledR}$ notes with comments and point allocations were transcribed into a data spreadsheet and analyzed for descriptive statistics and top scoring comments from each room.

Results: 85-91 attendees participated in the three breakout sessions resulting in 674 comments with 3,744 assigned value points. The top five scoring comments from each room per session $(N=45)$ determined stakeholder's most critical views. Stop comments made up the smallest total comments proportion (19\%), yet largest top scoring comment proportion $(36 \%)$ - potentially highlighting unified frustration for various massage education practices. Comparatively, Start comments made up $26 \%$ of total comments, but the smallest highest scoring proportion (18\%)-perhaps suggesting stakeholders feel it more important to improve what is already being done rather than beginning new endeavors in these areas.

†Supplemental materials available at http://ijtmb.org
Conclusion: Stakeholder opinions on the future of massage therapy education can be systematically gathered in large conference settings and organized, analyzed, and disseminated to inform field decision-making.

KEY WORDS: therapeutic massage; community participatory research; REDCap; massage education; massage policy; medical-based massage therapy; massage regulation; massage standards

\section{INTRODUCTION}

The current United States (US) massage field climate seeks for massage therapists to be recognized as health-care professionals. ${ }^{(1,2)}$ Massage has been practiced to support general and specific health from its beginning, ${ }^{(3)}$ yet its current inclusion in usual health care is not typical, nor is a health-care setting a typical practice venue for modern US massage therapists; ${ }^{(4,5)}$ although integrative models for massage therapy in medical settings do exist. ${ }^{(6)}$ Massage's usual noninclusion in health care may be due, in part, to inconsistent massage therapist credential specifications across the country ${ }^{(7)}$ which inhibits health-care integration potential and practices. The massage research literature has documented the field's concern for lack of consistent standards in the profession for nearly two decades, ${ }^{(8-10)}$ and multiple individual and collaborative efforts from various professional massage organizations and stakeholder groups have sought to elevate the massage field's standing through competency and training measures (e.g., Massage Therapy Body of Knowledge $[\mathrm{MTBOK}],{ }^{(11,12)}$ Entry-Level Analysis Project [ELAP], ${ }^{(13)}$ National Teacher Education Standards Project [NTESP] $\left.{ }^{(14)}\right)$. While the massage profession's improvement through elevated education standards is important, education and standards should not be the sole mechanism for change. Indeed, Wardle et al. ${ }^{(15)}$ point to the need for a broader agenda within the massage field, including attention to "upstream factors such as more active collaboration between researchers, clinicians, and policy-makers" (p.8), for overall 
profession improvement. Instances of such collaborative efforts exist and have resulted in publications that provide symposium activities documentation ${ }^{(10)}$ and results, ${ }^{(16,17)}$ as well as field recommendations $(9,10,18)$ and challenges articulation. $(2,9,18,19)$

The US therapeutic massage and bodywork field seems to be at a professional precipice regarding the direction of its education and practice with regard to health care. Will the massage field work to professionally align itself to work with and in medical health-care settings and practice; remain as is with no definitive and recognized professional credential or qualification for work with and in medical health-care settings and practice; or shift completely away from alignment as complementary to medical health-care settings and practice? Progress toward one direction or the other seems arrested, perhaps due in part to the diversity of options and opinions coupled with unsystematic discussion, vision, and decision dissemination from multiple field stakeholders. Additional research collaboration with massage education, practice, and policy stakeholders could help to collect, organize, and disseminate opinions, views, and recommendations to stoke informed field progress.

The Future of MT and Bodywork Forum was held July 27 during the 2017 Alliance for Massage Therapy Education (AFMTE) Educational Congress in Tucson, Arizona. ${ }^{(20)}$ A systematic approach was developed to gather the thoughts and opinions of the various massage education stakeholder forum attendees during an exercise following the principles of the World Café model, mixed with elements of speed dating. The key aspects of a World Café approach to discussion are: "Set the context, create hospitable space, explore questions that matter, encourage everyone's contribution, connect diverse perspectives, listen together for patterns and insight, and share collective discoveries". ${ }^{(21,22)}$ Multiple 20- to 30-min-long facilitated dialogues around a handful of topics is a hallmark of World Café and can take a fairly substantial amount of time. For situations in which multiple topics are on a discussion docket, elements indicative of speed dating can be used to allow multiple topics to be discussed and considered by everyone in a large group in a relatively short period. Forum activities, including the World Café-meetsspeed-dating-exercise highlighted in this paper, were developed and approved by the Congress organizers, and were not originally planned or conducted for research purposes. However, the opportunity for the planned efforts to become research were recognized and realized. The forum was facilitated by author Diane Mastnardo and was divided into four parts:

Part I. Setting the landscape-Big picture introduction and overview of current practice acts, policies, and predicted labor statistics.

Part II. Setting the landscape for the Educational Congress: What we have heard from our members? Perspective from schools, employers, independent contractors (IC), and continuing education (CE) providers.

Part III. Looking into the Future: World Café exercise (described in Methods).

Part IV. Bringing it all together: Looking for patterns and insights to share discoveries.

The organization, analysis, and dissemination of data collected as part of the 4-hr forum was intended to assist in progressing the massage field. Participants were attendees at the Congress, and included individuals engaged and involved in each of the Congress's stakeholder organizations (Associated Bodywork \& Massage Professionals: ABMP, AFMTE, American Massage Therapy Association (AMTA), Commission on Massage Therapy Accreditation (COMTA), Federation of Massage Therapy Boards (FSMTB), Massage Therapy Foundation (MTF), National Certification Board of Therapeutic Massage \& Bodywork (NCBTMB), Academic Collaborative for Integrative Health (ACIH), and American Organization of Bodywork Therapies of Asia (AOBTA), and represented massage therapists, students, educators, and employers. Congress attendees span all sectors of massage-related professional organizations, education frameworks and delivery platforms, and employment, each with varying experience related to health-care delivery, receipt, and complementary therapy integration. The diverse population of massage education stakeholders expected to attend the Congress suggested a viable and broad source from which opinions regarding massage field progression needs could be collected. The forum exercise asked participants to consider, document, and assign value to their thoughts on what should be done differently, more, started, and stopped in regard to massage foundation education, continuing education, and employment. Forum attendees and exercise participants earned $4 \mathrm{hrs}$ of continuing education credit for these conference activities.

Prior to the forum, the Indiana University Institutional Review Board provided review and approval as Exempt for the forum's data gathering exercise protocol (\#1706190124) which occurred during the forum's Part III. The forum and World Café exercise was developed by lead authors DM and NM, with input from AFMTE over the course of four months. DM developed the procedures for and led the forum and exercise, and NM attended the forum, observed and documented exercise activities, and designed the analysis plan for the data.

The purpose of the World Café forum exercise was to systematically collect, organize, and report what massage therapy education stakeholders believe is most important for foundation massage education, continuing massage education, and massage employment to move the field forward, in a positive direction. It is hoped that the process described here 
can be replicated in future conference settings to systematically gather, organize, and consider more related feedback from various groups. This paper aims to provide a descriptive report of the forum exercise's 1) methods and rationale, 2) participant and participation descriptions, and 3 ) results for what massage therapy education stakeholders feel is most important to progress the field in a positive direction. The efforts described here reflect a successful collaboration led and facilitated by author DM between a community massage therapist and researcher volunteer, a massage field organization, and a trained professional researcher with the skills, expertise, and resources to design, conduct, analyze, and disseminate research.

\section{METHODS}

Methods described include an online voluntary forum exercise participant descriptor survey, the World Café forum exercise, and the quantitative aspects of the project's analysis plan. While qualitative data analysis is planned and in progress, only quantitative aspects are included in this initial descriptive report.

\section{Online Voluntary Forum Exercise Participant Descriptor Survey}

During Parts I and II of the 4-hr forum, attendees were asked to access an anonymous REDCap ${ }^{(23)}$ survey via their smartphones, electronic devices or computers, to answer a few descriptive, but nonidentifying, questions. REDCap (Research Electronic Data Capture) is a secure, web-based application designed to support data capture for research studies, providing: an intuitive interface for data entry; audit trails for tracking data manipulation and export; and automated export procedures. ${ }^{(23)}$ The survey consisted of six questions collecting respondent's age, highest level of education, years (if any) involved in the massage field and education field, and various, generic affiliations (current and previous) such as massage or other field therapist, employer, or educator. Data were collected and used only to describe forum participants and attendees. See Supplementary Materials Appendix A for the full anonymous survey.

\section{Forum World Café Exercise}

The World Café-based exercise occurred during Part III of the forum and was allotted $1 \mathrm{hr}$ and $40 \mathrm{~min}$. Three, concurrent 30-min Breakout Group Sessions took place in three different, adjacent rooms. Each room was assigned an exercise facilitator, timekeeper, and framing topic: Continuing Education (CE), Schools, and Employment. Each of the concurrent 30-min Breakout Group Sessions had the following components, each led by the room facilitator:
- Greetings and introduction to the room's topic (CE, Schools, or Employment)

- Review of the exercise

- Exercise (detailed below)

- Thanks and next steps

Participants who engaged in the entire forum World Café exercise completed the procedures described below a total of three times, once in each framing topic room (Rounds I-III). Participants were administered index cards with two specific room rotation features: 1) card color, and 2) a letter (A, B, C, D) or number (i, ii, iii, iv) which indicated starting room and table assignment and subsequent room rotation assignments. Table 1 is the master rotation assignment schedule that was used and could be adapted to other similar exercises so as to mix participant interactions. At the start of the second and third Round, room facilitators had participants count off $1,2,3,4, a, b, c, d$, to indicate at which table (Stop, Start, More, Different) each participant would begin in that room (i.e., 1s and a-s begin at Stop table, $2 \mathrm{~s}$ and $\mathrm{b}-\mathrm{s}$ begin at Start table, etc.). For the within-room table rotations, people with letter assignments would rotate to the left and those with number assignments rotated to the right. These inter- and intraround rotation schedules were intended to mix people throughout the process and promote communication comfort, particularly for those with less experience; the fear being that dominant voices and/or personalities would overshadow or intimidate less gregarious or experienced participants. Room assignments were posted in each room, and room facilitators answered questions throughout and managed participant movement between, and within, Round rotations.

Table 1. World Café Exercise Master Rotation Schedule

\begin{tabular}{lcc}
\hline & Round 1 & \\
CE Room & Employment Room & Schools Room \\
i, ii, iii, iv & i, ii, iii, iv & i, ii, iii, iv \\
A, B, C, D & A, B, C, D & A, B, C, D \\
& Round 2 & \\
CE Room & Employment Room & Schools Room \\
i, ii i, ii & i, ii iii, iv & iii, iv iii, iv \\
C, D C, D & A, B C, D & A, B A, B \\
& Round 3 & \\
CE Room & Employment Room & Schools Room \\
A, B A, B & i, ii iii, iv & i, ii i, ii \\
iii, iv iii, iv & A, B, C, D & C, D C, D \\
\hline
\end{tabular}

Prior to the exercise, participants received a colored index card (green, purple, or yellow) with either a letter or number. For each Round I-III, participants followed the color and letter/number rotation on their card per the Master Schedule which was posted in each room. 


\section{Exercise procedures description}

Participants completed four rotations per exercise round following their rotation "map." Within-Round rotations were between large tables, each assigned with a Different, More, Start, or Stop question to consider related to the room's framing topic (Schools, CEs, Employment). Rotation durations were tapered to the "speed dating-like" schedule presented in Table 2. Table 3 outlines each room's Different, More, Start, and Stop question; each table had its corresponding question noted on it for participants to consider and discuss amongst themselves.

TABle 2. Per Round Rotation Time Allotments

\begin{tabular}{lc}
\hline Rotation & Minutes \\
\hline 1 & 3 \\
2 & 2.5 \\
3 & 2 \\
4 & 1.5 \\
\hline
\end{tabular}

A tapered "speed-dating" approach was used to promote and capture initial, genuine response and discourage potentially distracting rumination.
Tables contained up to two large Post-it ${ }^{(\mathbb{R}}$ note charts, each accommodating 3-8 participants at any given time. Participants wrote their responses to each table's question on the table's large Post-it ${ }^{\circledR}$ note chart with a marker. As participants rotated through the four different table sets, they would review and add on to the previous groups' comments on the charts. After four rounds, all participants had the opportunity to consider and comment on each of that room's questions. For the time remaining in the 30-min session, participants were asked to add importance values to the various comments made for each of the questions in that room by placing weighted colored dots next the comments they felt were most important. Orange dots were of most importance and weighted with 3 points, while Blue dots were important and worth 1 point. Participants were issued 6 blue and 3 orange dots as they entered each of the three Round (topic) rooms; dots were not intended to transfer between rooms or Rounds and were intended to only be assigned to comments made within their distributed room. Author Munk moved from room to room throughout the World Café exercise to document room and per-table participant counts using a paper/pencil form developed

Table 3. Room and Table Prompt Questions

\begin{tabular}{ccc}
\hline $\begin{array}{c}\text { Question } \\
\text { Type }\end{array}$ & Continuing Education Room & Employer Room \\
Questions & Questions & Suestions \\
\end{tabular}

Different

More

Start What are the things the massage and massage and bodywork field currently conducts Continuing Education that should be done DIFFERENTLY to improve the field's chance of future growth \& prosperity? (tweaked or changed)

What are the ways in which the massage and bodywork field currently conducts Continuing Education that should be kept and done MORE to improve the field's chance of future growth \& prosperity? (increase, expand or do even better) bodywork field should START doing that are currently not being done related to Continuing Education to improve the field's chance of future growth $\&$ prosperity?

Stop What are the ways in which the massage and bodywork field currently conducts Continuing Education that should $\underline{\text { STOP }}$ in the future to improve the field's chance of future growth $\&$ prosperity?
What are the current Employment opportunities in the massage and bodywork field that should be done DIFFERENTLY to improve the field's chance of future growth $\&$ prosperity? (tweaked or changed)

What are the Employment opportunities in the massage and bodywork field that we should have MORE of in the future to improve the field's chance of future growth \& prosperity?

What are Employment opportunities in the massage and bodywork field that we should START doing that we are currently not doing to improve the field's chance of future growth $\&$ prosperity?

What are the current Employment opportunities in the massage and bodywork field that should be

STOPPED to improve the field's chance of future growth $\&$ prosperity?
What are the current SCHOOL related practices and policies that should be done differently with regard to training entry level massage and bodywork practitioners in the future?

What are the current SCHOOL related practices and policies that should be kept and done more of with regard to training entry level massage and bodywork practitioners in the future?

What SCHOOL related practices and policies are currently NOT being done but should be started in the future related to training entry level massage and bodywork to improve the field's chances of future growth and prosperity?

What are the current SCHOOL related practices and policies that should be stopped with regard to training entry level massage and bodywork practitioners? 
specifically for the purpose (see Supplementary Materials Appendix B).

\section{Analysis Plan}

Analysis plans were developed by author NM and completed by authors NM and JDD.

\section{Voluntary descriptor survey}

Data from the REDCap survey were exported into an Excel spreadsheet and descriptive statistics were completed using standard Excel statistical features. No identifiers were collected with the survey, nor were survey responses linked to exercise comments or point allocations.

\section{World Café exercise data}

Each Post-it ${ }^{\circledR}$ note sheet was labeled with its breakout session Round, room, and question type between forum Parts III and IV, and displayed for all participants to consider and discuss among themselves. After the forum, the Post-it ${ }^{\circledR}$ note sheets were collected and transported to Indiana University's IUPUI campus for three further steps of organization and analysis.

1. Data management design: an Excel data system platform for data management and storage was designed and developed for all gathered data from all the exercises.

2. Data entry and organization: each hand-written comment was typed into the project's master Excel spreadsheet, along with assigned dot numbers and value. Data observation identification numbers were assigned at the comment level, with each comment observation including originating Post-it ${ }^{\circledR}$ note descriptors (specifically, breakout session Round, room focus, and question type).

3. Descriptive statistics: computed with standard Excel statistical features and SAS 9.3 for a) participant counts and awarded points per possible points and per breakout session Round and room focus, and b) comment and point counts per breakout session Round, room focus, and question type, respectively. Descriptive statistics were also computed on the top five scoring comments (45 total extracted comments) from each room during each breakout session Round as a way to quantify what participants determined the most critical points. The top five scoring comments from each room per Round was used, instead of the top total scoring 40 (or otherwise) comments, to account for the potential of scores to be artificially inflated in rooms with either few comments and/or higher participant counts (more points divided among fewer comments produces the potential for higher overall scores that could mute relatively high scores coming out of other rooms/round).

\section{RESULTS}

The forum exercise took approximately $1 \mathrm{hr}$ and 45 min, and occurred after lunch on the first day of the conference. One hundred thirty-four individuals registered for the conference, including several of those who were also affiliated with one of the 22 exhibit booths. Approximately 109 attendees $(81 \%)$ attended the first two aspects of the forum (nonexercise portion), and 90-95 attendees participated in Rounds I-III for the exercise. Ninety, 87, and 85 attendees provided comments and point allotments in the CE, Employment, and School rooms, respectively. Approximately 100 conference attendees took part in the final forum aspect which discussed the forum exercise and field status in directed roundtable brainstorming activities.

The remainder of the results section is broken down into three parts, each addressing this paper's results dissemination objectives: describe the exercise participants, data gathering exercise procedural descriptive statistics, and top scoring participant provided exercise comments.

\section{Participant Descriptors}

Sixty-five $(n=65)$ forum attendees/exercise participants accessed and completed the voluntary participant descriptor survey, resulting in an approximate $75 \%$ response rate. Respondents ranged in age from 23 to 73 years $($ mean $=51)$, and a majority $(89 \%)$ held an Associate's degree or higher. Most respondents $(86 \%)$ were or had been massage therapists, and 61 respondents reported 1.5-45 yrs of experience in, or with, the massage field (respondents averaged 21 years massage experience). Sixty respondents reported 1-45 yrs of experience or involvement in the education field (respondents averaged 16 yrs education experience). Respondents were or had been foundation massage instructors $(42 \%)$, massage continuing education providers $(60 \%)$, massage school owners $(22 \%)$, massage business owners (38\%), and massage organization board members (32\%). Nonmassage field-related yet relevant roles reported by respondents included chiropractor, $\mathrm{RN}$, social worker, instructors for yoga, chiropractic, aromatherapy, and acupuncture foundation and continuing education training, business recruiter, publisher, and student. Respondents averaged five affiliations each, and $94 \%$ reported more than one affiliation. Participant descriptor survey respondents were not asked their gender; however, participant counts collected during the exercise on developed study forms (see Supplementary Materials Appendix B) indicated that approximately $23 \%(n=21)$ of exercise participants were men.

\section{Data Gathering Exercise Procedural Descriptive Statistics}

The data-gathering exercise resulted in 674 total comments distributed among 59 large Post-it notes 
sheets each containing 2-30 unique comments (median $=11$ comments) on each sheet, and 3,744 total value points awarded by 2,240 total sticker dots that participants affixed beside comments they felt were important (blue dots worth 1 point) and critical (orange dots worth 3 points). Table 4 reports participant counts for each room and round, along with possible and actual assigned points. Based on participant numbers, there were 3,930 possible allocation points for the forum exercise for which 5\% (186) were unassigned. Eighteen percent $(\mathrm{n}=124)$ of comments had no importance dots affixed to them and were scored 0 . Thirty-five percent $(\mathrm{n}=238)$ of comments had a score of 5 or greater, and $8 \%(n=57)$ of comments had a score above 12 .

Table 5 displays the forum exercise's various breakdowns of comment and point allotments by primary categories Round, Question Type, and Room, as well as the within group count and point allocations. The School room had the highest proportion of comments per round for each of the forum exercise's three Rounds, but each room had the highest point proportion in at least one round in accordance with high participant counts (more points to distribute) and/or lower unassigned point proportions. Start and Stop comments were evenly distributed among rooms, while comment proportion distributions were similar for the Difference and More comments, with the School room having the highest comment proportion followed by Employer and CE rooms. Overall point allocations across Rounds, Question Type, and Room were even. More and CE comments were allotted the greatest proportion of allocated points for their respective groups, while Difference and School

TABLE 4. Participant and Point Counts and Percentages

\begin{tabular}{|c|c|c|c|c|}
\hline & $\begin{array}{c}\text { Participant } \\
\text { Count }\end{array}$ & $\begin{array}{c}\text { Possible } \\
\text { Points }^{a}\end{array}$ & $\begin{array}{c}\text { Actual Points } \\
\text { Awarded- } \\
3,744 \\
\text { (\% of } \\
\text { Possible) }\end{array}$ & $\begin{array}{c}\text { Unassigned } \\
\text { Points } \\
-186 \\
\\
\text { (\% of } \\
\text { Possible) }\end{array}$ \\
\hline CE Room & 90 Total & 1350 & $1314(97 \%)$ & $36(3 \%)$ \\
\hline Round 1 & 29 & 435 & $430(99 \%)$ & $5(1 \%)$ \\
\hline Round 2 & 28 & 420 & $397(95 \%)$ & $23(5 \%)$ \\
\hline Round 3 & 33 & 495 & $487(98 \%)$ & $8(2 \%)$ \\
\hline Employer Room & 87 Total & 1305 & $1223(94 \%)$ & $82(6 \%)$ \\
\hline Round 1 & 31 & 465 & $421(91 \%)$ & $44(9 \%)$ \\
\hline Round 2 & 28 & 420 & $428(>100 \%)$ & 0 \\
\hline Round 3 & 28 & 420 & $374(89 \%)$ & $46(11 \%)$ \\
\hline School Room & 85 Total & 1275 & $1207(95 \%)$ & $68(5 \%)$ \\
\hline Round 1 & 31 & 465 & $493(>100 \%)$ & 0 \\
\hline Round 2 & 30 & 450 & $370(82 \%)$ & $80(18 \%)$ \\
\hline Round 3 & 24 & 360 & $344(96 \%)$ & $16(4 \%)$ \\
\hline
\end{tabular}

aPossible points based on 15 participant count. Each participant was issued 6 blue and 3 orange dots at the start of each round (blue dots $=1$ point; orange dots $=3$ points). comments were allotted the least proportion of allocated points for their respective groups.

\section{Top Scoring Comments}

Forty-five top scoring comments were identified from the exercise. The top five scoring comments from each room per Round (15 total comments per focus topic) are organized by question type and room

TABLE 5. Comment and Point Counts per Round, Room, and Question Type

\begin{tabular}{|c|c|c|}
\hline & $\begin{array}{c}\text { Comment Counts (\%) } \\
N=674\end{array}$ & $\begin{array}{c}\text { Point Counts (\%) } \\
N=3744\end{array}$ \\
\hline Round 1 & $269(40 \%)$ & $1344(36 \%)$ \\
\hline $\mathrm{CE}$ & $60(22 \%)$ & $430(32 \%)$ \\
\hline Employer & $97(36 \%)$ & $421(31 \%)$ \\
\hline School & $112(42 \%)$ & $493(37 \%)$ \\
\hline Round 2 & $209(31 \%)$ & $1195(32 \%)$ \\
\hline $\mathrm{CE}$ & $70(33 \%)$ & 397 (33\%) \\
\hline Employer & $65(31 \%)$ & $428(36 \%)$ \\
\hline School & $74(35 \%)$ & $370(31 \%)$ \\
\hline Round 3 & $196(29 \%)$ & $1205(32 \%)$ \\
\hline $\mathrm{CE}$ & $66(34 \%)$ & $487(40 \%)$ \\
\hline Employer & $54(28 \%)$ & $374(31 \%)$ \\
\hline School & $76(39 \%)$ & $344(29 \%)$ \\
\hline Different Comments & $161(24 \%)$ & $866(23 \%)$ \\
\hline $\mathrm{CE}$ & $43(27 \%)$ & $280(32 \%)$ \\
\hline Employer & $54(34 \%)$ & $303(35 \%)$ \\
\hline School & $64(40 \%)$ & $283(33 \%)$ \\
\hline More Comments & $208(31 \%)$ & $1075(29 \%)$ \\
\hline $\mathrm{CE}$ & $49(24 \%)$ & $422(39 \%)$ \\
\hline Employer & $66(32 \%)$ & $328(31 \%)$ \\
\hline School & $93(45 \%)$ & $325(30 \%)$ \\
\hline Start Comments & $178(26 \%)$ & $919(25 \%)$ \\
\hline $\mathrm{CE}$ & $63(35 \%)$ & $280(30 \%)$ \\
\hline Employer & $53(30 \%)$ & $314(34 \%)$ \\
\hline School & $62(35 \%)$ & $325(35 \%)$ \\
\hline Stop Comments & $127(19 \%)$ & $884(24 \%)$ \\
\hline $\mathrm{CE}$ & $41(32 \%)$ & $332(38 \%)$ \\
\hline Employer & $43(34 \%)$ & $278(30 \%)$ \\
\hline School & $43(34 \%)$ & $274(31 \%)$ \\
\hline CE Room & $196(29 \%)$ & $1314(35 \%)$ \\
\hline Different & $43(22 \%)$ & $280(21 \%)$ \\
\hline More & $49(25 \%)$ & $422(32 \%)$ \\
\hline Start & $63(32 \%)$ & $280(21 \%)$ \\
\hline Stop & $41(21 \%)$ & $332(25 \%)$ \\
\hline Employer Room & $216(32 \%)$ & $1223(33 \%)$ \\
\hline Different & $54(25 \%)$ & $303(25 \%)$ \\
\hline More & $66(31 \%)$ & $328(27 \%)$ \\
\hline Start & $53(25 \%)$ & $314(26 \%)$ \\
\hline Stop & $43(20 \%)$ & $278(23 \%)$ \\
\hline School Room & $262(39 \%)$ & $1207(32 \%)$ \\
\hline Different & $64(24 \%)$ & $283(23 \%)$ \\
\hline More & $93(35 \%)$ & $325(27 \%)$ \\
\hline Start & $62(24 \%)$ & $325(27 \%)$ \\
\hline Stop & $43(16 \%)$ & $274(23 \%)$ \\
\hline
\end{tabular}


in Table 6. The highest proportion of top scoring comments $(36 \%)$ were responses to Stop-related questions, with those related directly to foundation and continuing education making up the majority (75\%). Seventy-five percent of comments from the CE room were those responding to Stop or More questions, while only a single top scoring comment from the School and CE room were in response to More and
Start questions, respectively. The lowest proportion of top scoring comments $(18 \%)$ were responses to Start questions, and the majority of top scoring comments $(63 \%)$ were responses to Stop and More questions. Top scoring comments from the School and CE rooms clearly responded to the "what about the current way massage education is conducted" prompt, while most comments coming out of the Employer room focused

TABLE 6. Top 45 Scoring Comments per Question Type and Room $(\mathrm{n}=45)$

\begin{tabular}{|c|c|c|}
\hline Question & Room & Comment \\
\hline \multirow[t]{3}{*}{ Start } & $\mathrm{CE}$ & Self-care classes/ergonomics \\
\hline & Employer & $\begin{array}{l}\text { Higher pay for degrees/education beyond the basics } \\
\text { Mentorship opportunities }\end{array}$ \\
\hline & School & $\begin{array}{l}\text { Increase massage program hours and length of program } \\
\text { Focusing on self-care. Instructors they teach what they live (emotional and energetic) } \\
\text { Created higher Ed pathway from AAS, to BS to MS to PhD Ed } \\
\text { Promote teacher cert. for their instructors } \\
\text { Professional attire and behavior }\end{array}$ \\
\hline \multirow[t]{3}{*}{ Different } & $\mathrm{CE}$ & $\begin{array}{l}\text { CE provider teacher education } \\
\text { Stop inventing your own technique }\end{array}$ \\
\hline & Employer & $\begin{array}{l}\text { Reciprocity of licensure bet[ween] states } \\
\text { Support research efforts } \\
\text { Offer benefits } \\
\text { More cash for therapists w/ specialized training }\end{array}$ \\
\hline & School & $\begin{array}{l}\text { More extensive internships/externships/clinic hours(supervised) } \\
\text { Accreditation is the norm } \\
\text { Don't pass everyone }\end{array}$ \\
\hline \multirow[t]{3}{*}{ More } & $\mathrm{CE}$ & $\begin{array}{l}\text { People skills diversity of options standardized one approval } \\
\text { Business CE's practice } \\
\text { More EB research integrated in course material } \\
\text { Apprenticeship for specialization(sports) } \\
\text { More evidence based content } \\
\text { Providers attend ongoing CE programs improve teaching skills }\end{array}$ \\
\hline & Employer & $\begin{array}{l}\text { Affiliated with health care environment } \\
\text { Principle based learning vs. technique-based learning } \\
\text { Therapist friendly scheduling } \\
\text { Mentoring training program } 1^{\text {st }} 3 \text { years } \\
\text { Build bridges MD and Hospitals }\end{array}$ \\
\hline & School & More critical and creative/thinking skills integrated into curriculum \\
\hline \multirow[t]{3}{*}{ Stop } & $\mathrm{CE}$ & $\begin{array}{l}\text { Stop random regulating (CE providers) non-portability of CE credits between states Recertification need to be } \\
\text { less complicated } \\
\text { Inter-organizational fighting about CE oversight } \\
\text { Stop online hands on instruction } \\
\text { Approving everything } \\
\text { Stop approving unqualified instructors/courses like online unsupervised practice }\end{array}$ \\
\hline & Employer & $\begin{array}{l}\text { Under paying therapists } \\
\text { Overworking therapists (no breaks and } 7 \text { hours of massage) } \\
\text { Booking massage on the hour (every hour) } \\
\text { Selling product requirements }\end{array}$ \\
\hline & School & $\begin{array}{l}\text { Dumbing down the curriculum } \\
\text { Ignoring evidence-based research } \\
\text { Inconsistent grading or passing students that don't meet the requirements } \\
\text { Unqualified instructors in classroom (no experience training teaching skills } \\
\text { Moving students to T.A. and teaching roles prematurely } \\
\text { Training for less than ELAP standard }\end{array}$ \\
\hline
\end{tabular}


on noneducation-related employer practices such as employee benefits, treatment, and fit into employer business model.

\section{DISCUSSION}

Months of planning went into the World Cafébased exercise included as part of The Future of MT and Bodywork Forum held during the 2017 AFMTE Educational Congress. In addition to forum and exercise planning, IRB approval was sought and awarded to systematically collect, analyze, and disseminate the data produced by the exercise in an effort to add to the developing evidence base related to massage field stakeholder views. While the Congress forum was not originally planned or completed for research purposes, the potential for information generated by the data gathering exercise to become research was realized through planning and documentation. To our knowledge, this is the first formal massage-related conference proceeding to purposively design, plan, and complete a systematic process to collect, organize, analyze, and disseminate massage education stakeholders' opinions on what needs to be done to improve the massage field moving forward. By sharing this process and the procedures for the World Café-based exercise, other massage-related gatherings or conferences could replicate the exercise and report their findings.

The forum exercise enjoyed robust participation, with approximately $65 \%$ of registered attendees participating at any given time, and nearly all of the possible importance points were awarded in each room during each round. Attendees to the 4-hr forum, during which the 1.5 hour World Café-based exercise occurred, had the freedom to enter and leave the activities as they chose. While participant count reduced for each exercise round, there was only a $5.6 \%$ overall attrition rate by Round III and $75 \%$ of registered attendees participated in the final Part IV and closure of the forum, suggesting perhaps that this was a generally positive engagement experience for participants. The comment counts for each breakout session Round progressively decreased, which corresponds with decreasing participants, but may also indicate high initial enthusiasm for the activity that either progressively waned or that, with practice, comments became more focused on important matters. Indeed, the later assumption is likely, given that progressively fewer numbers of 0 scoring comments came out of 2nd and 3rd breakout session Rounds.

The exercise participants brought a wealth of experience and knowledge to their consideration of the questions in each breakout session room. While not all exercise participants completed the voluntary descriptor survey, those who did offer a glimpse into the depth of massage and education experience that informed comments and value dot allotments. With massage experience averaging more than 20 years and an average of five related affiliations, many exercise participants are and/or have been massage therapists, business owners, school owners, instructors, and CE providers. This breadth of experience contributed to insightful and direct comments in general and those deemed most important (top scoring). It should not go unrecognized that while Stop comments made up the smallest proportion of total comments $(19 \%)$, comments responding to Stop questions made up the largest proportion of the top scoring comments (36\%). Top scoring Stop proportions would have been even higher had Stop-related comments recorded in other question categorizations (i.e., "Stop inventing your own technique," and "Don't pass everyone," were responses to Different questions) been included. High top scoring Stop comments such as stop ... "online hands on instruction," "approving everything," "under paying [and "overworking"] therapists," "dumbing down the curriculum," "ignoring evidence based research," "inconsistent grading or passing students that don't meet the requirements," and "unqualified instructors in classroom" may highlight a unified frustration for various massage stakeholders in the way aspects of the massage profession are currently operating, particularly in relation to foundation and continuing education which each had $38 \%$ of the top scoring Stop comments (75\% total). Top scoring Stop-focused comments from the School room seemed focused on elevating assessment standards for students and instructors. Start comments made up over a quarter and second-highest proportion of total comments, but had the smallest proportion (18\%) of the highest scoring comments, perhaps suggesting stakeholders feeling it more important to improve what is already being done rather than beginning new things in these areas. Like the Stop focused comments, those top scoring Start comments from the School room also seemed focused on assessment and standards improvements for students and instructors.

Two specific top scoring comments from the Employer-focused room highlighted stakeholders feelings that more alignment with medical-related health care was important to progress the massage field in a positive way: Employers should be more "affiliated with health-care environment" and building more bridges to/with "MD[s] and [h] ospitals." These sentiments certainly support the field's progression "direction" towards professional alignment to work with, and in, medical health-care settings and practice. A limiting factor in this trajectory, however, is likely therapist preparation and suitability to work in a medical-related health-care environment ${ }^{(24)}$ _ an issue potentially ameliorated by addressing top scoring comments highlighting the need to improve massage foundation and continuing education standards. The development of specific hospital-based training courses $^{(24)}$ speaks to the massage field's need and 
desire for such employment environment preparation, in addition to competency articulation efforts such as those by the Hospital Based Massage Therapy task force within ACIH. The task force recently released a set of competencies for massage therapy in hospital settings ${ }^{(25)}$ based on a 2014 convenience sample survey of hospital-based massage therapy programs. ${ }^{(26)}$ The top scoring health care-related comments highlight the likely agreement between massage therapy stakeholders and these sample efforts to align the massage field with health care.

Our results support and add to prior findings that increased research and increasing research's role in the massage field is important to the field's positive progress. ${ }^{(2,9)}$ Top scoring comments, such as employers should "support research efforts," and schools should stop "ignoring evidence based research," among others, highlight stakeholders value placement on research. Massage therapists are generally supportive of research in the field, but their comfort with, and skill at, accessing, assessing, utilizing, or contributing to research is relatively weak. ${ }^{(27,28)}$ The research endeavor is complex with varying roles and skill sets needed to perform a continuum of aspects. For example, it is one thing for an individual to "consume" (i.e., access, read, understand, and apply) research; needed skills are less involved and potentially easier to master than those needed to design, collect, analyze, and disseminate research. Likewise, research participation is equally varied in its involvement, roles, and skill set, but can be intimidating at any level when the process and expectations are unknown. The exercise described here provided an opportunity for a relatively large number of massage therapy stakeholders to participate in a meaningful research endeavor as part of a fun and relaxed conference proceeding, in addition to removing (we hope) potentially intimidating or negative research perceptions. With this and other dissemination efforts, these research participants will have the opportunity to see the impact of their participation in research by seeing comments they either made themselves or added value points to. The fact that several top scoring comments focused on research importance to progress the field in a positive way may suggest, too, that our efforts to engage potentially reluctant massage therapy stakeholders with research were successful.

\section{Limitations and Future Steps}

The efforts described here have several limitations and generalizations from this data to other massage field populations should be made with caution. Best efforts were made to describe participants through the anonymous participant descriptor survey forum attendees were invited to complete via their smart devises. However, the extent to which survey respondents participated in the exercise or valued the top scoring comments is unknown. The data generated through this exercise came from a small number of people given the size of the massage therapy field. In addition, the focused nature of the Congress setting (specific to massage education) likely was less representative of the overall numbers in the field interested in massage education given the average $20+$ years of massage and $16+$ years of education experience among the sample. At least $80 \%$ of survey responders were directly involved with massage education at some point in their careers, whether as a foundation massage or massage $\mathrm{CE}$ instructor, massage school administrator, and/or massage school owner. These numbers highlight that individuals directly involved in massage therapy education were disproportionately represented in this work, which is certainly not representative of general massage therapist populations. These proportions would perhaps not be found at larger, national field conventions, or similar and broader field-reflective input may provide additional insight into directions massage education and employment should go moving forward.

The intention of the exercise questions was to focus participants on what needed to be done in regard to each rooms' focus/topic for the massage and bodywork field's future growth and prosperity chances. While an education relation was obvious for Schools and CE room questions, the link to education for the Different, More, Start, and Stop questions in the Employment room were less clear, resulting in question framing and responses pertaining to employer rather than education practices. Replications of this exercise with focused interest on education should consider framing employmentrelated questions from the standpoint of education to make therapists more employable or better, more valuable employees. We suggest the following Different, More, Start, and Stop questions for future use: What are the ways in which the massage therapy and bodywork field currently trains/educates entrylevel practitioners that should be done differently to better prepare them for employment? What are the ways in which the massage therapy and bodywork field currently trains/educates entry-level practitioners that should be done more to prepare them for employment? What are things that should be started by the massage therapy and bodywork field with how entry-level practitioners are trained/educated to better prepare them for employment? What are the ways in which the massage therapy and bodywork field currently train/educates entry-level practitioners that should be stopped to better prepare them for employment? Questions framed as suggested here would better elicit stakeholder responses focused on employment-related educational needs rather than practices. Responses for employment-related educational needs would better inform the field of therapist employee skills gaps experienced in industry and which perhaps limit massage career progression and opportunity. 
This paper's purpose is to provide a descriptive report for three aspects of the World Café-based exercise conducted in the 2017 Education Congress: 1) methods and rationale, 2) participant and participation descriptions, and 3) results. Only descriptive statistics have been applied to the quantitative data (value assignment for individual comments) and reported thus far. We anticipate an additional wealth of information to be gleaned by applying qualitative analysis methods to the collected data, and are in process of these analysis steps. Consideration of the top 45 scoring comments and their categorization provides general guidance about what massage education stakeholders feel is important for the massage field to move forward. Additional qualitative analysis may provide a more richly considered and clearer focused direction forward for the massage field's unified efforts.

\section{CONCLUSION}

This is the first time the World Café method has been combined with components of speed dating to systematically collect, organize, consider, and disseminate the opinions of experienced and invested massage therapy stakeholders with regard to moving the field forward in a positive way. These efforts were collaborative between conference planners and volunteers, with a professional researcher working in an academic and research supportive environment allowing for the data cleaning, organization, analysis, and dissemination to be expedited relatively quickly. Future opportunities to lend or provide financial support for those in positions to complete and disseminate research would likely be a sound and worthy investment which could contribute to infrastructure-building for research career paths in the field - an aspect highlighted as important by the National Center of Complementary and Integrative Medicine's 2016 Strategic Plan. ${ }^{(29)}$

The World Café-meets-speed-dating-exercise and analysis process described here can be replicated in future conference type settings of varying size to inform field leadership of overarching stakeholder sentiment on what should be stopped, started, done more of or differently in the field. This initial experience with the described process determined that educationrelated field stakeholders place the most value on things needing to Stop with regard to continuing education, foundation school, and employment practices to move the massage field forward in a positive way. High valued Stop assertions seem to highlight unified frustration from these stakeholders for situations in which related regulatory policy changes would likely elevate the field in general and also in the view of peer fields, the public, and health-care provider professions. It would be interesting to see whether the high valued comments of other massage stakeholder populations highlight similar concerns and we hope to have, or others will take, the opportunity to replicate this process in other conference settings.

\section{ACKNOWLEDGMENTS}

Special acknowledgement is extended to the Alliance for Massage Therapy Education (AFMTE) Board of Directors, planning committee, and participants of the Educational Congress for providing their support and input, respectively. We would also like to acknowledge Sandra Anderson, Regina Cobb, and Whitney Lowe for facilitating the room rotations and breakout groups. This work was supported in part by Indiana University's Department of Health Sciences for Dr. Munk's effort, and the IUPUI Undergraduate Research Opportunities Program (UROP) for Jasmine Dyson-Drake's effort.

\section{CONFLICT OF INTEREST NOTIFICATION}

The Alliance for Massage Therapy Education (AFMTE) hosted The Future of MT and Bodywork Forum and approved the forum exercise described in the manuscript. All data organization, analysis, and interpretation occurred independent of AFMTE or other massage therapy professional affiliations. Financial support for author JDD's work on the project was awarded by the IUPUI Undergraduate Research Opportunities Program (UROP). Author NM is a Kentucky state licensed massage therapist, Massage Therapy Foundation Trustee, AMTA member, and ACIH Research Work Group member. Author DM was a member of the AFMTE Congress Planning Committee and is a NCBTMB Board Certified Massage Therapist, ABMP member, and ACIH Education Work Group member.

\section{COPYRIGHT}

Published under the CreativeCommons AttributionNonCommercial-NoDerivs 3.0 License.

\section{REFERENCES}

1. Benjamin PJ. The Emergence of the Massage Therapy Profession in North America: A History in Archetypes. Toronto, ON: Curties-Overzet Publications; 2015.

2. Shroff FM, Sahota IS. How can massage therapy move forward? Registered massage therapists touch on key points shaping their profession in British Columbia, Canada. Home Health Care Manage Pract. 2012;24(4):182-192.

3. Goldstone LA. Massage as an orthodox medical treatment past and future. Complement Ther Nurs Midwifery. 2000;6(4): 169-175. 
4. American Massage Therapy Association (AMTA). Massage Therapy Industry Fact Sheet. Evanston, IL: AMTA; 2017. Available from: https://www.amtamassage.org/ infocenter/economic_industry-fact-sheet.html. Accessed April 8, 2018.

5. Kania-Richmond A, Reece BF, Suter E, Verhoef MJ. The professional role of massage therapists in patient care in Canadian urban hospitals - a mixed methods study. BMC Complement Altern Med. 2015;15(1):20.

6. Rodgers NJ, Cutshall SM, Dion LJ, Dreyer NE, Hauschulz JL, Ristau CR, et al. A decade of building massage therapy services at an academic medical center as part of a healing enhancement program. Complement Ther Clin Pract. 2015;21(1):52-56.

7. Associated Bodywork \& Massage Professionals (ABMP). Massage \& Bodywork State Licensing Requirements. Golden, CO: ABMP; 2018. Available from: https://www.abmp.com/ practitioners/state-requirements. Accessed April 8, 2018.

8. Hymel GM. Advancing massage therapy research competencies: dimensions for thought and action. J Bodywk Movement Ther. 2003;7(3):194-199.

9. Kania-Richmond A, Menard MB, Barberree B, Mohring M. "Dancing on the edge of research"-What is needed to build and sustain research capacity within the massage therapy profession? A formative evaluation. J Bodywk Movement Ther. 2017;21(2):274-283.

10. Moyer CA, Dryden T, Shipwright S. Directions and dilemmas in massage therapy research: a workshop report from the 2009 North American Research Conference on Complementary and Integrative Medicine. Int $J$ Therap Massage Bodywk. 2009;2(2):15.

11. Fong B, Lavery M, Pierce K, Salvo S, Schenkman S, Schmidt D, et al. Massage Therapy Body of Knowledge. MTBOK; 2010. Available from: www.MTBOK.org. Accessed April 5, 2018.

12. Sefton JM, Shea M, Hines C. Developing, maintaining, and using a body of knowledge for the massage therapy profession. Int J Therap Massage Bodywk. 2011;4(3):1.

13. Coalition of National Massage Therapy Organizations. ELAP: Entry-Level Analysis Project [for the massage profession]. 2012. Available from: http://www.elapmassage.org/. Accessed April 9, 2018.

14. Alliance for Massage Therapy Education. National Teacher Education Standards Project. Tuscon, AZ: AFMTE; 2017. Available from: https://www.afmte.org/education/ntesp/. Accessed April 9, 2018.

15. Wardle JL, Barnett R, Adams J. Practice and research in Australian massage therapy: a national workforce survey. Int $J$ Therap Massage Bodywk. 2015;8(2):2.

16. Kennedy AB, Cambron JA, Sharpe PA, Travillian RS, Saunders RP. Clarifying definitions for the massage therapy profession: the results of the Best Practices Symposium. Int J Therap Massage Bodywk. 2016;9(3):15.

17. Kennedy AB, Cambron JA, Sharpe PA, Travillian RS, Saunders RP. Process for massage therapy practice and essential assessment. J Bodywk Movement Ther. 2016;20(3):484-496.
18. Grant KE, Balletto J, Gowan-Moody D, Healey D, Kincaid $\mathrm{D}$, Lowe $\mathrm{W}$, et al. Steps toward massage therapy guidelines: a first report to the profession. Int J Therap Massage Bodywk. 2008;1(1):19-36.

19. Menard MB. Choose wisely: the quality of massage education in the United States. Int $J$ Therap Massage Bodywk. 2014;7(3):7-24.

20. Alliance for Massage Therapy Education. 2017 Educational Congress, July 2017, Tuscon, Arizona. Tuscon, AZ: AFMTE; 2017. Available from: https://www.afmte.org/2017-educational-congress/. Accessed April 9, 2018.

21. The World Cafe Community Foundation. Cafe-To-Go-Revised. Greenbrae, CA: The Foundation; 2015. Available from: http:// www.theworldcafe.com/wp-content/uploads/2015/07/Cafe-ToGo-Revised.pdf. Accessed March 25, 2018.

22. Brown J, Isaacs D. The World Café: Shaping Our Futures Through Conversations That Matter, 1st ed. San Francisco, CA: Berrett-Koehler Publishers; 2005.

23. Harris PA, Taylor R, Thielke R, Payne J, Gonzalez N, Conde JG. Research electronic data capture (REDCap) — a metadatadriven methodology and workflow process for providing translational research informatics support. $J$ Biomed Informatics. 2009;42(2):377-381.

24. Dion LJ, Cutshall SM, Rodgers NJ, Hauschultz JL, Dreyer NE, Thomley BS, et al. Development of a hospital-based massage therapy course at an academic medical center. Int J Ther Massage Bodywk. 2015;8(1):25-30.

25. Academic Collaborative for Integrative Health (ACIH). ACIH Hospital Based Massage Therapy (HBMT) Competencies for Optimal Practice in Integrated Environments. Whitefish, MT: ACIH; 2017. Available from: https://integrativehealth.org/ publications/. Accessed April 8, 2018.

26. Brennan, MK, Healey, D, Tague C, Rosenthal B. Hospital Based Massage Therapy: A Call for Competencies. MASSAGE Magazine 2016. Available from: https:/www.massagemag.com/ hospital-based-massage-therapy-call-competencies-37084/

27. Gowan-Moody DM, Leis AM, Abonyi S, Epstein M, Premkumar K. Research utilization and evidence-based practice among Saskatchewan massage therapists. J Complement Integrat Med. 2013;10(1):189-198.

28. Baskwill AJ, Dore K. Exploring the awareness of research among registered massage therapists in Ontario. J Complement Integrat Med. 2016;13(1):41-49.

29. National Center for Complementary and Integrative Health. NCCIH 2016 Strategic Plan. Bethesda, MD: NCCIH; 2016. Available from: https://nccih.nih.gov/sites/nccam.nih.gov/files/ NCCIH_2016_Strategic_Plan.pdf. Accessed April 5, 2018.

Corresponding author: Niki Munk, PhD, LMT, Department of Health Sciences, School of Health and Human Sciences, Indiana University - IUPUI, 1050 Wishard Blvd, RG 3001, Indianapolis, IN 46202, USA E-mail:nmunk@iu.edu 